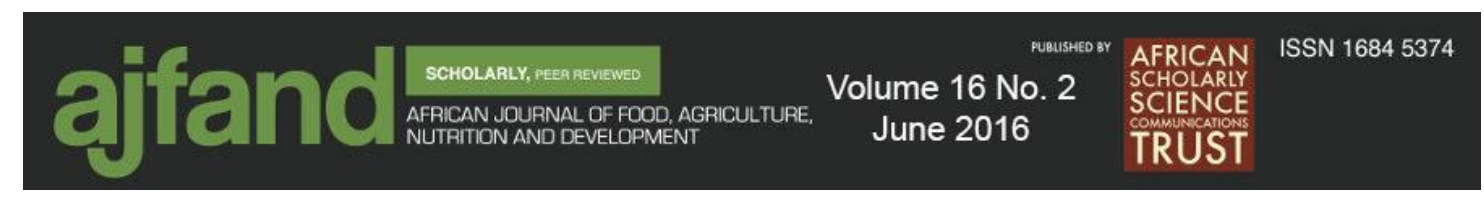

DOI: $10.18697 /$ ajfand.74.13755

\title{
MORPHOLOGICAL DIVERSITY OF MANGO GERMPLASM FROM THE UPPER ATHI RIVER REGION OF EASTERN KENYA: AN ANALYSIS BASED ON NON- FRUIT DESCRIPTORS
}

\author{
Toili MEM ${ }^{1 *}$, Rimberia FK ${ }^{2}$, Nyende AB ${ }^{1}$ and D Sila ${ }^{3}$
}

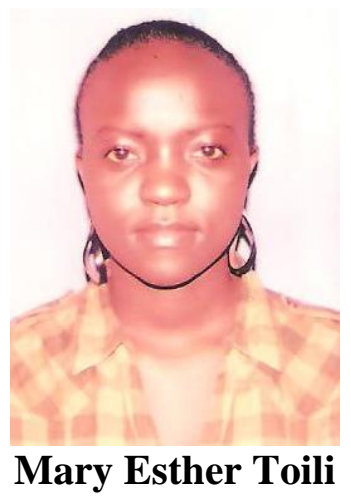

*Corresponding author email: essytoili@gmail.com

${ }^{1}$ Institute for Biotechnology Research, Jomo Kenyatta University of Agriculture and Technology (JKUAT), P.O. Box 62000-00200; Nairobi, Kenya

${ }^{2}$ Department of Horticulture, Jomo Kenyatta University of Agriculture and Technology, P.O. Box 62000-00200; Nairobi, Kenya

${ }^{3}$ Department of Food Science and Technology, Jomo Kenyatta University of Agriculture and Technology, P.O. Box 62000-00200; Nairobi, Kenya 


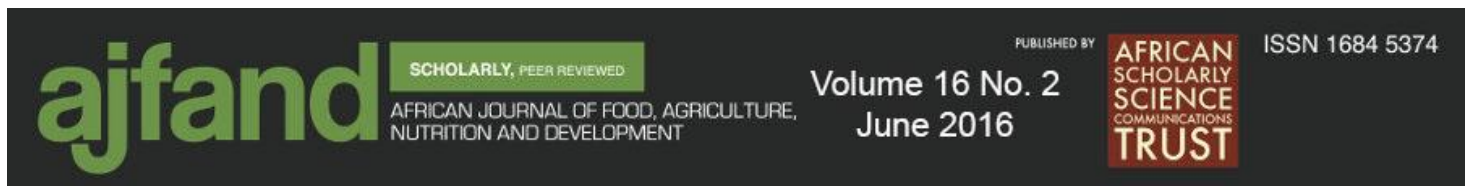

\begin{abstract}
Phenotypic variation in plants can be evaluated by morphological characterization using visual attributes. Fruits have been the major descriptors for identification of different varieties of fruit crops. However, even in their absence, farmers, breeders and interested stakeholders require to distinguish between different mango varieties. This study aimed at determining diversity in mango germplasm from the Upper Athi River (UAR) and providing useful alternative descriptors for the identification of different mango varieties in the absence of fruits. A total of 20 International Plant Genetic Resources Institute (IPGRI) descriptors for mango were selected for use in the visual assessment of 98 mango accessions from 15 sites of the UAR region of eastern Kenya. Purposive sampling was used to identify farmers growing diverse varieties of mangoes. Evaluation of the descriptors was performed on-site and the data collected were then subjected to multivariate analysis including Principal Component Analysis (PCA) and Cluster analysis, one- way analysis of variance (ANOVA) and Chi square tests. Results classified the accessions into two major groups corresponding to indigenous and exotic varieties. The PCA showed the first six principal components accounting for $75.12 \%$ of the total variance. A strong and highly significant correlation was observed between the color of fully grown leaves, leaf blade width, leaf blade length and petiole length and also between the leaf attitude, color of young leaf, stem circumference, tree height, leaf margin, growth habit and fragrance. Useful descriptors for morphological evaluation were 14 out of the selected 20; however, ANOVA and Chi square test revealed that diversity in the accessions was majorly as a result of variations in color of young leaves, leaf attitude, leaf texture, growth habit, leaf blade length, leaf blade width and petiole length traits. These results reveal that mango germplasm in the UAR has significant diversity and that other morphological traits apart from fruits can be useful in morphological characterization of mango.
\end{abstract}

Key words: Mango, morphological characterization, Principal Component Analysis, IPGRI, eastern Kenya 


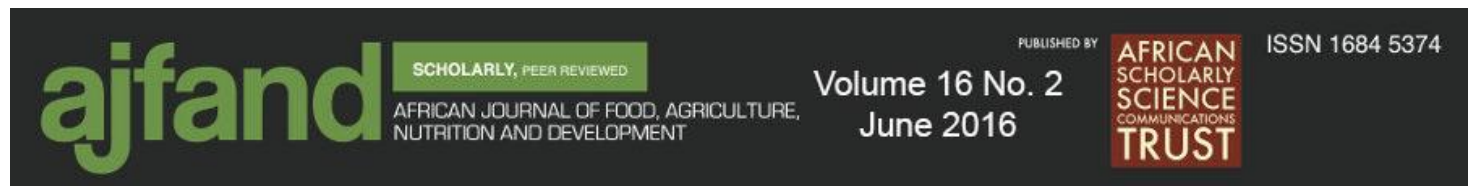

\section{INTRODUCTION}

Mango (Mangifera indica L.), a native of southeast Asia, is one of the important fruit crops in the tropical and subtropical lowlands thought to have been introduced to East Africa in the $14^{\text {th }}$ century [1]. Currently, mango has been listed as the third most important fruit crop after bananas and pineapples in terms of area and total production in Kenya [2]. The increasing demand for the fruit is due to the fruit's high vitamin, mineral and fiber levels besides the value-added products made from it. Consequently, the fruit brings economic benefits from both local sales and foreign earnings upon export [2].

Mango has been reported to have extensive diversity due to alloploidy, outbreeding, repeated grafting and phenotypic differences arising from varied agro-climatic conditions in different mango growing regions [3]. The important commercial mango varieties introduced in Kenya from USA, Australia, Israel and other countries remain to be fully characterized and adopted for cultivation in different regions. In addition, cross pollination in mango could have resulted in new varieties not yet documented [4]. Subsequently, mango varieties' characterization has experienced great confusion in nomenclature with many synonyms existing for the same varieties. Further, while geneticists and plant breeders are particularly interested with diversity at the molecular level, agronomists are more concerned with how visible morphological and agronomic variations can be used for sustainable farming [5]. In addition, farmers are faced with the challenge of identifying cultivars that are productive for their agro-ecological zones because they are unfamiliar with the characteristics of the many different cultivars of mango that are now grown and available in the country, resulting in lower productivity $[4,6,7]$.

Morphological characterization is thus a simple, formal and standardized method of identifying and presenting mango's genetic diversity [8]. Assessment of morphological variation in fruit crops usually requires the availability of fruits [4]. The fruiting season is unfortunately limited for most fruit crops. However, even in the off-fruiting season, farmers, grafters, nursery managers and breeders still require to discriminate mango varieties in such times as during selection and discrimination of rootstock or even during artificial pollination. This necessitates the identification of mango vegetative descriptors that can be used in the absence of fruits. This study's objective was to determine diversity in mango germplasm from the UAR, a region in Kenya growing both local and improved varieties, using descriptors for mango plant that excluded fruit characteristics. This will enable the effective utilization of mango's genetic resources especially in breeding programs for sustainable improvement of this crop.

\section{MATERIALS AND METHODS}

\section{Survey and sampling}

A targeted baseline survey was conducted in 15 sites of the UAR in the period of April and May 2011 and a second survey conducted between April and May 2012. These included: Ikalyoni, Ikangavya, Itumbole, Kasikeu, Kasunguni, Kikoko, Kilala, Kiou, Kithangathini, Kyamusoi, Kyanginywa, Mbiuni, Sekereni, Wautu and Wote. 


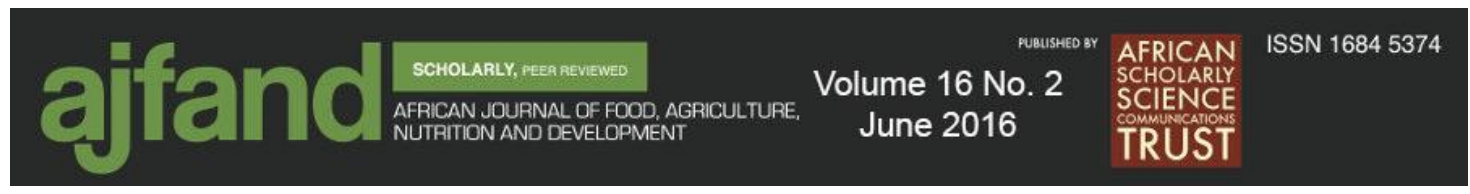

Meetings with mango farmers were organized with the help of the agricultural extension officers in the region. A purposive sampling targeting farmers who cultivated diverse varieties of mangoes was then used to select 24 farms growing both indigenous and exotic varieties for evaluation of morphological diversity. A total of 98 accessions representing 21 different varieties were identified in the farmers' orchards and used in the morphological evaluation (Table 1).

\section{Data collection}

Mango accessions were visually evaluated on site using the International Plant Genetic Resources Institute (IPGRI) descriptors for mango [9]. The attributes of interest were recorded on a data sheet and pictures of the same were recorded. These included measurements on tree height, stem circumference, tree growth habit (angle at which the main branches join the stem) and crown shape. For the leaves, the leaf attitude, color of young and fully mature leaves (CYL and CFL), fragrance strength, leaf blade shape (LBS), leaf blade length (LBL), leaf blade width (LBW), petiole length, leaf apex shape (LAS), leaf base shape, leaf margin type, leaf texture, pelvinus thickness, leaf pubescence, angle of secondary veins to midrib and presence of secondary veins were evaluated (Table 2).

The tree height was measured with the help of a ladder to a height of $10 \mathrm{~m}$. Trees taller than that were labeled as 'over $10 \mathrm{~m}$.' Stem circumference was measured at $50 \mathrm{~cm}$ above the ground on mature trees. Leaf blade length was determined from an average of ten mature leaves per tree, measured from the base to the tip of the leaf blade. The leaf width was determined by measuring the widest part of the leaf blade for ten leaves per tree. The petiole length was also measured as an average of ten leaf petioles per tree, measured from the base of the leaf blade to the stem. Fragrance strength was determined from a fully matured leaf when crushed. All other attributes including colors, habits and shapes were evaluated using IPGRI visual appraisals, with the colors for young leaves being determined on newly sprouted shoots while the colors of fully grown leaves were evaluated on normal-looking fully matured leaves (on an average of ten leaves per tree sample).

\section{Statistical analysis of data}

Qualitative data was summarized and processed descriptively using means and percentages. Chi-square and one-way analysis of variance (ANOVA) were conducted to asses any significant difference among the qualitative and quantitative traits for the different accessions using the Statistical Package for Social Scientists (SPSS) version 18 [10]. Significance level was set at 0.01 . The data was further submitted to principal component analysis (PCA) using the XLSTAT 2013.2.04 statistical package. A dendrogram was then inferred using Agglomerative hierarchical clustering (AHC- single linkage) based on a Euclidian distance dissimilarity matrix.

\section{RESULTS}

The 21 mango varieties used in this study are sub-classified into three categories according to a report by the Food and Agricultural Organization [11]. The first category was composed of nine indigenous varieties; Dodo, Kasukari, Katili, Kitui, Mombasa, 


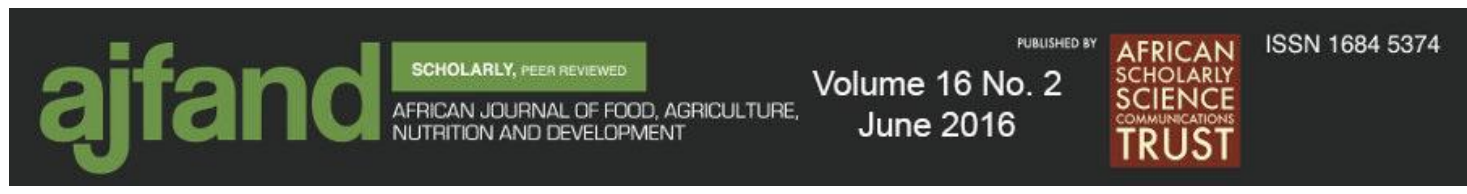

Ndoto, Sikio la punda and two others whose names were not identified (Indigenous I and Indigenous II). The second category was made up of nine exotic varieties namely Haden, Keitt, Kent, Maya, Nimrod, Sabine, Sensation, Tommy Atkins and Vandyke. Finally, the third category was made up of indigenous varieties that have been commercially adopted by farmers in the region namely Apple, Batawi and Ngowe. The indigenous varieties are propagated by seed while the remaining varieties are grafted.

Results of this study reveal that mango germplasm cultivated in the UAR region of Eastern Kenya possesses extensive morphological diversity (Plate 1). 

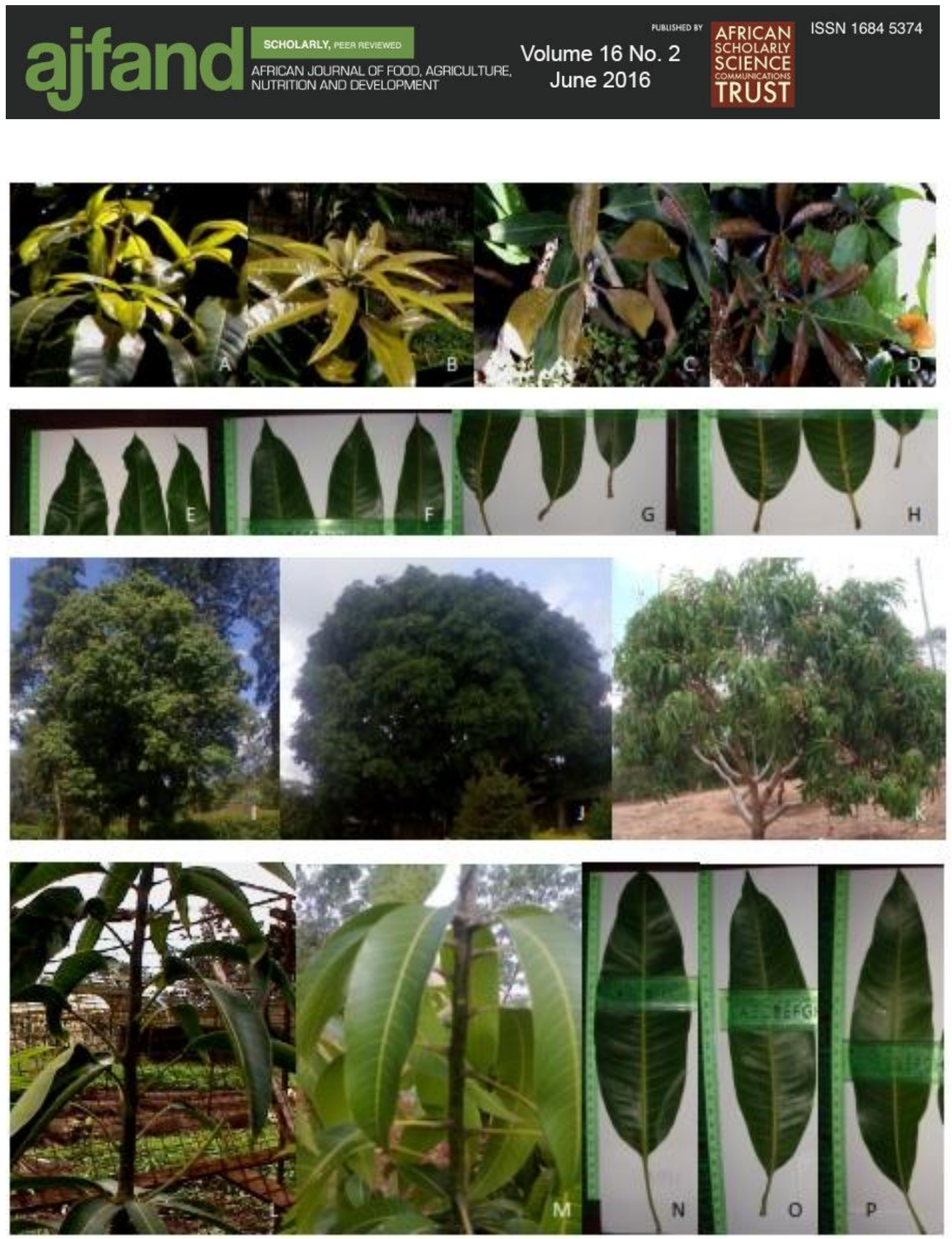

Plate 1: Morphological diversity observed in mango accessions from the UAR region of eastern Kenya. A-D: Color of young leaves (Light green, Light green with brownish tinge, Reddish brown, Deep coppery tan); E-H: Leaf characters (Acute apex with wavy margin, Acuminate apex with entire margin, Acute base, Obtuse base); I-K: Crown shapes (Oblong, Semicircular, Spherical); L-M: Leaf attitude (Semi-erect, Horizontal); N-P: Leaf shapes (Elliptic, Lanceloate, Lanceolate/Oblong)

The leaves of the mango trees were majorly elliptic in shape $(62.8 \%)$ with an obtuse leaf base shape (84.9\%), an entire leaf margin $(77.9 \%)$ and chartaceous texture $(68.6 \%)$. A leaf blade shape not described before by IPGRI was also observed in $33.7 \%$ of the accessions. 


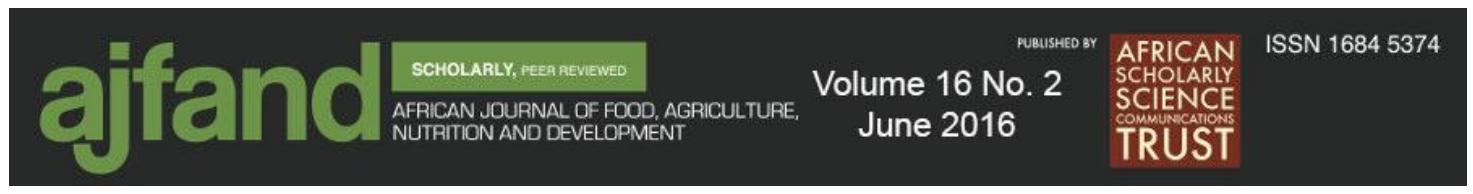

This shape combined the characters of lanceolate and oblong shapes (Table 3). Further, leaf fragrance was absent in $83.7 \%$ of the accessions. Tree growth habit was mainly spreading (65.1\%) and the crown shape was mostly semi-circular (69.8\%). The most significant of these qualitative traits included leaf attitude, leaf texture and growth habit at $\mathrm{P}<0.01$. The individual qualitative characteristics of the 21 varieties are presented in Table 4. Observed measurement ranges for the quantitative characters revealed that LBL, LBW and petiole length were most significant at $\mathrm{P}<0.01$ (Table 5). However, some descriptor traits namely pelvinus thickness, leaf pubescence, angle of secondary veins to midrib and presence of secondary veins on leaf presented only a single phenotypic class. The relationship among the accessions was illustrated by the agglomerative hierarchical clustering dendogram derived from cluster analysis (Figure 1). The first branch in the hierarchy grouped the accessions into two clusters. Cluster $1(n=17)$ was composed only of indigenous varieties; Mombasa, Kasukari, Katili, Dodo, Indigenous I, Ndoto, Indigenous II, Sikio la punda and Kitui. These accessions had a mean leaf blade length, width and petiole length of $19.28 \mathrm{~cm}, 5.43 \mathrm{~cm}$ and $5.122 \mathrm{~cm}$, respectively. Further, the leaf margin type for most accessions was wavy and the leaves exuded a mild fragrance. The trees were all non-grafted and showed a mean stem circumference of 92.62 inches and a mean height of over $10 \mathrm{~m}$. Cluster $2(\mathrm{n}=81)$ was made up of the exotic varieties and the indigenous but commercially adopted varieties. This cluster was further divided into smaller sub-clusters $2 \mathrm{a}$ (green-colored section) and $2 \mathrm{~b}$ (blue-colored section). Subcluster 2a was made up of seven varieties namely Nimrod, Ngowe, Sabine, Tommy, Van Dyke, Batawi and Haden while sub-cluster 2b was composed of Apple, Kent, Keitt, Maya, Sensation and single accessions of Ngowe (013N3) and Batawi (02B) varieties. The accessions in this cluster had a mean leaf blade length, width and petiole length of $16.47 \mathrm{~cm}, 4.42 \mathrm{~cm}$ and $4.59 \mathrm{~cm}$, respectively. Fragrance from the leaves was absent and leaf margin type was mainly entire. The trees were all grafted and exhibited a mean tree height and stem circumference of $4.7 \mathrm{~m}$ and 32.36 inches, respectively. 

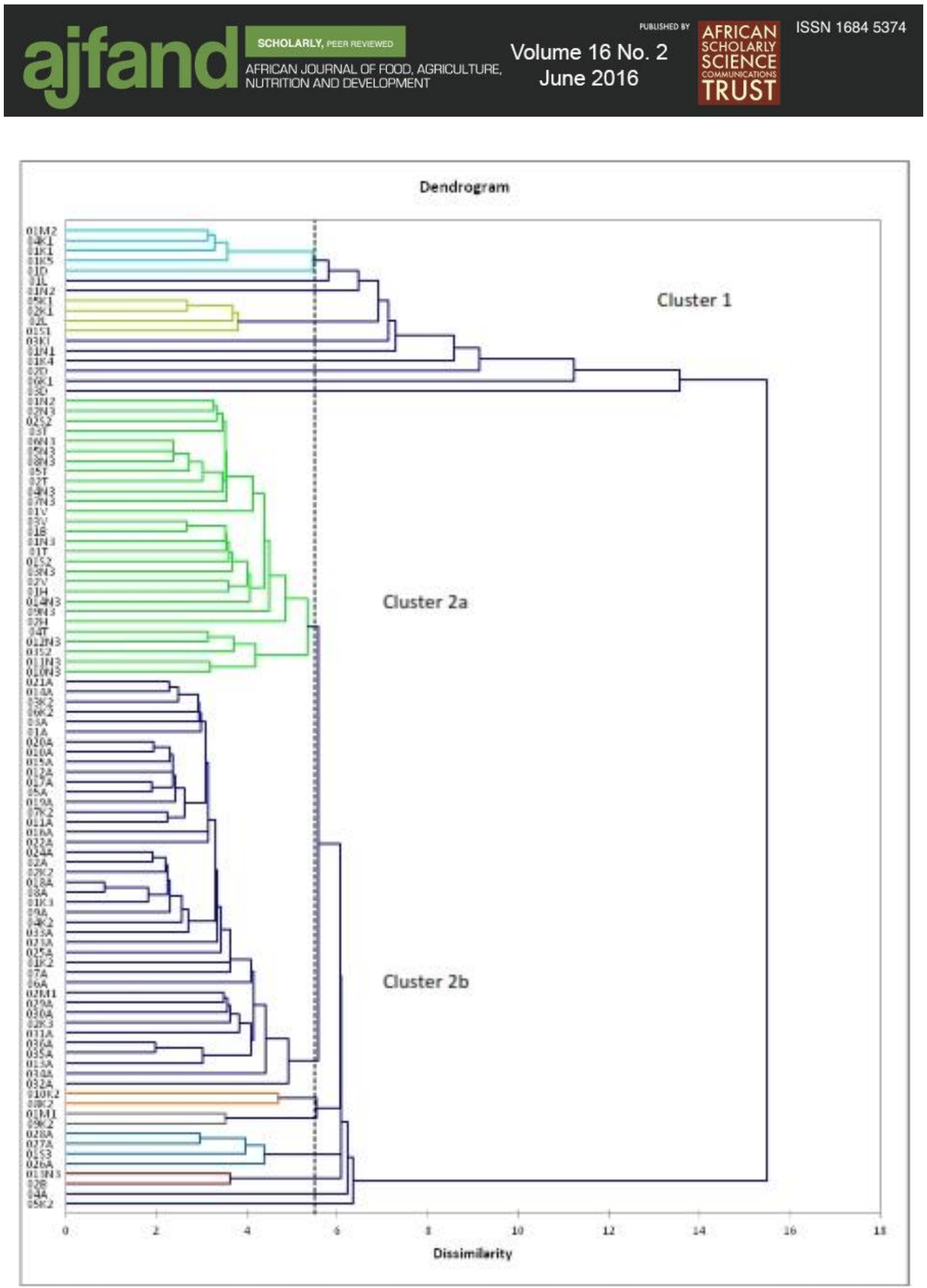

Figure 1: Dendrogram based on morphological characters of mango accessions from the UAR region of eastern Kenya using the single linkage and Euclidian distance

From the PCA, the first six principal components axes took into account $75.12 \%$ of the total variance in the studied accessions, with eigen values ranging between +5.238 to +0.975 (Table 6). 


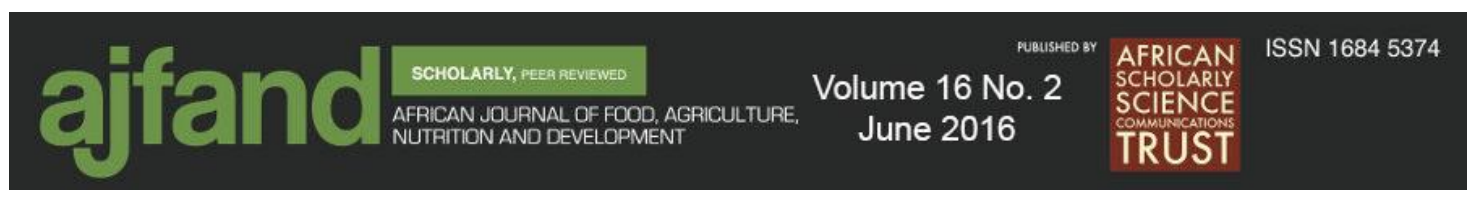

The traits that contributed most weight to the first principal component axis were the leaf margin, fragrance strength, tree height, stem circumference and color of young leaf. The second principal component axis was associated mainly with the LBL, LBW and leaf texture. The traits that contributed most weight to the third principal axis were LBS, LAS and CFL whereas LBS, petiole length and CFL contributed the most weight to the fourth principal component axis. The LBS, petiole length, leaf attitude and leaf texture contributed the most weight to the fifth principal component axis and finally, petiole length, leaf attitude and growth habit contributed the most weight to the sixth principal component. The association among morphological traits was revealed by the PCA plot (Figure 2). Here, the angle size between two or more traits is directly proportional to correlation between these characters, that is, the closer the traits are to each other, the higher the correlation. Consequently, a high correlation was observed between traits related to the CFL, LBW, LBL and petiole length. A high correlation was also observed between traits related to the leaf attitude, CYL, stem circumference, tree height, leaf margin, growth habit and fragrance. 

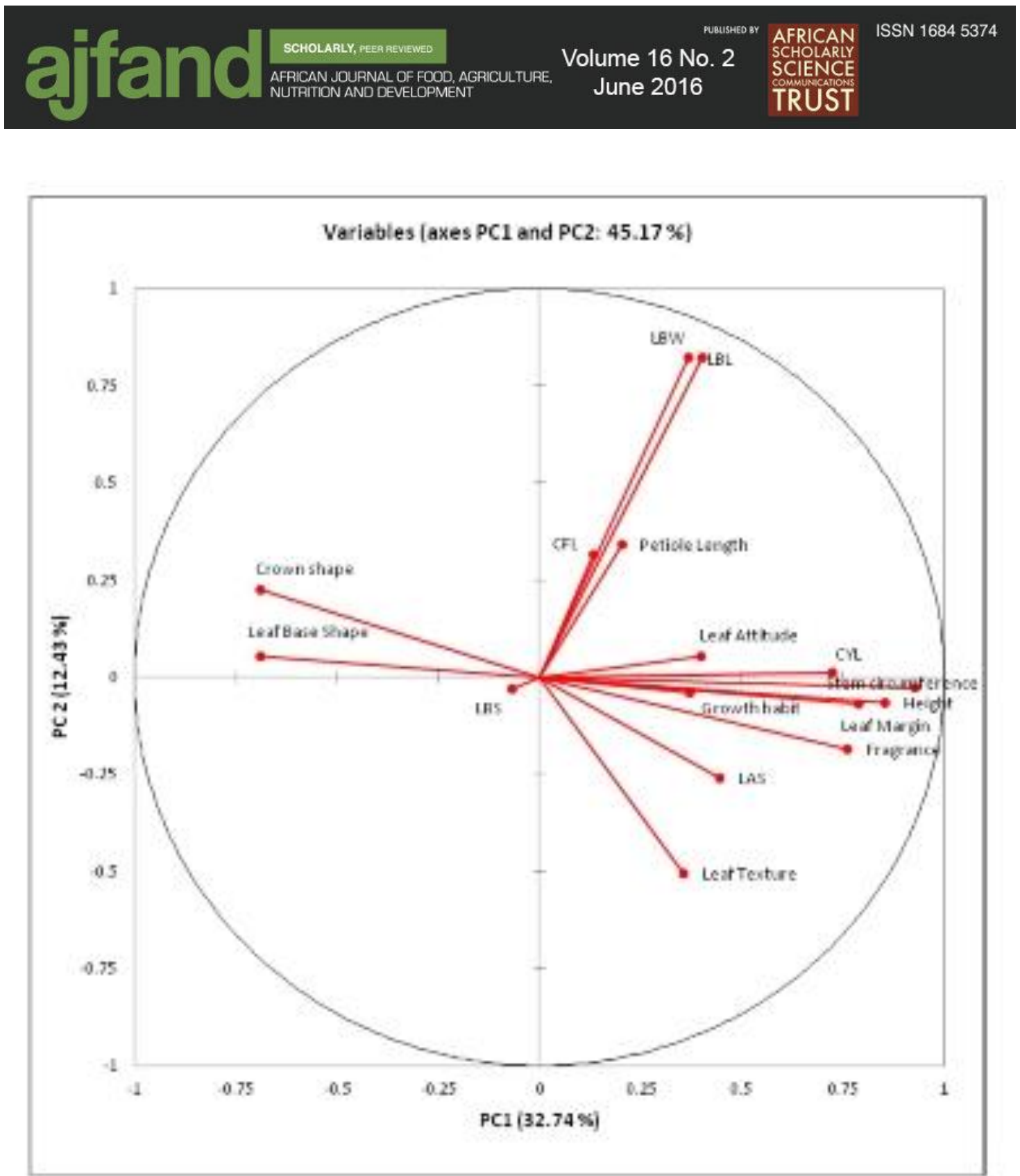

Figure 2: PCA plot showing the association among characters correlated with the first and second Principal Components, accounting for 32.74\% and $12.43 \%$, respectively

Key: $\quad$ CFL-Color of fully mature leaf, CYL-Color of young leaf, LAS-Leaf apex shape, LBS-Leaf blade shape, LBL-Leaf blade length, LBW-Leaf blade width

Combining results from the PCA, ANOVA and Chi-square tests, the most important morphological traits that were useful in discriminating between varieties were identified. A total of 14 out of the 20 descriptors were considered to be useful and included; leaf margin type, fragrance strength, tree height, stem circumference, color of young leaf, leaf attitude, leaf texture, growth habit, leaf blade length, leaf blade width, petiole length, leaf blade shape, leaf apex shape and color of fully grown leaf. 


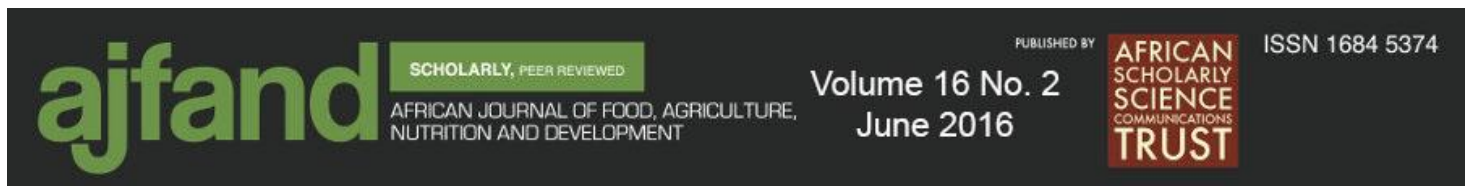

\section{DISCUSSION}

Morphological analysis based on non-fruit descriptors by IPGRI for mango were successfully used to distinguish between varieties. The accessions studied displayed varietal diversity evidenced by the existence of variations in the selected descriptor traits. These accessions further grouped into different clusters according to the morphological features associated with them. All the indigenous mango varieties clustered separately from the exotic and from the indigenous but commercially adopted varieties. This could be a result of the obvious differences displayed by the two groups such as tree height and circumference, leaf fragrance strength and even leaf and petiole sizes. Local varieties possessed significantly higher values of the above quantitative traits and exuded a strong fragrance from the leaves as compared to the exotic ones. Varieties derived from each cluster can be used as parents in breeding efforts. These should focus on increase of yield by development of disease, pest, and drought resistance [12].

The clustering of Apple, Ngowe, and Batawi together with the exotic varieties raises questions on their origin. These are local varieties, purported to have their roots in Tanzania/ Kenya [4, 6,13]. However, the close similarities (on non-fruit characteristics) displayed between these varieties and their exotic counterparts, highlights the possibility of a common ancestry. Apple, for instance, was closely similar to Kent, Keitt, Sensation (known to have their origin in Florida) and Maya (originating from Israel). Ngowe and Batawi on the other hand were similar to Nimrod (origin in Israel), Sabine, Tommy Atkins, Vandyke and Haden. The latter three are monoembryonic varieties known to have undergone selection in Florida. Sabine variety has also been reported to be a local variety with its origins in Tanzania [4]. However, reports by the Food and Agricultural Organization (FAO) and Agricultural Business Development (ABD) list this variety (including Apple) as exotic [11,14]. Available literature provides conflicting reports on the origin of these mangoes; this study, therefore, provides illumination on the possible ancestry of studied varieties.

Results presented in this study are particularly important because they represent morphological traits available all year round, some of which remain the same even at the seedling stage of the mango tree. This enables the identification of varieties at different stages of development. The most important traits deemed useful for this purpose, according to this study, include leaf margin type, fragrance strength, tree height, stem circumference, color of young leaf, leaf attitude, leaf texture, growth habit, leaf blade length, leaf blade width, petiole length, leaf blade shape, leaf apex shape and color of fully grown leaf. Similarly, studies in other countries also found tree height, petiole length and leaf width as significant traits $[15,16]$. As such, it is now possible to distinguish between seedlings in a nursery by observing traits such as the color of newly sprouting shoots. It has, however, been reported that parameters related to size such as leaf blade length and width or tree height are subjective to environmental conditions and thus their use for morphological discrimination is examined on case by case basis. This is unlike qualitative parameters that are less prone to environmental effects and are more variety-dependent [17]. This study is, therefore, less environmentally biased since 10 out of the 14 descriptors deemed useful for differentiating the accessions were qualitative and included leaf margin type, fragrance strength, tree height, color of young leaf, leaf 


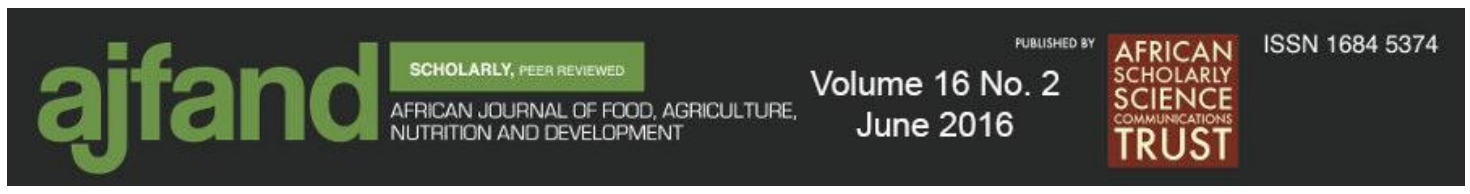

attitude, leaf texture, growth habit, leaf blade shape, leaf apex shape and color of fully grown leaf.

However, because each characteristic makes its contribution to the variability of an individual and no characteristic alone is responsible for total variation, the elimination of less informative descriptors should facilitate interpretations without causing substantial loss of information and ensure reductions in required resources, contributing to more accurate measurement of the most important traits for morphological characterization [18]. In this study, not all the IPGRI descriptors selected for morphological evaluation were useful for discrimination purposes. Some proved redundant, presenting only one phenotypic class. Pelvinus thickness, leaf pubescence, angle of secondary veins to midrib and presence of secondary veins on leaf were discarded. In the morphological analysis of papaya germplasm from Brazil, some descriptor traits for papaya proposed by International Board for Plant Genetic Resources (IBPGR), including presence/absence of leaf pubescence only displayed a single class and were excluded [19, 20]. In addition, other descriptors such as the type of crown shape and leaf texture were also not favorable for differentiation purposes. These could be influenced by management activities such as pruning and development age of the plant where younger trees may possess leaves that are softer and vice versa. Similarly, a study on the morphological characterization of mango from eastern and central Kenya reported that tree characteristics depended heavily on farmer activities and environmental conditions [20]. Further, it is imperative that continuous evaluation of germplasm is carried out for all species. A leaf blade shape not described by IPGRI was observed in the studied mango germplasm. This shape, which combined the attributes of lanceolate and oblong leaf shapes was observed in $30.6 \%$ of all varieties. Since these do not represent novel varieties, it is possible that adjustments are needed on the published descriptor traits to accommodate these observed morphological differences [15]. For the effective utilization of plant genetic resources in breeding or genetic improvement programs, understanding the germplasm is essential. The IPGRI descriptors allow for the use of visual assessment tools of morphological traits to characterize mango germplasm. However, complex plant characters such as yield are quantitatively inherited and are influenced by genetic effect as well as genotype/environmental interaction. This poses the need to identify and use highly correlated characters [21]. The color of fully grown leaf, leaf blade length, leaf blade width and petiole length; the leaf attitude, color of young leaf, stem circumference, tree height, leaf margin, growth habit and fragrance were some of the characters that had a strong correlation. These highly correlated traits can be utilized for the selection of mango with improved/ desired traits such as dwarf trees for easy fruit harvesting or spreading growth habit for easy orchard management [22]. In the study of other fruit crops, strong correlations were observed in traits related to petiole length and leaf size $[21,23,24]$. The diverse variable arrangements at the individual genotype level presents the opportunity of obtaining desirable trait combinations in specific cultivars through selection either directly or following recombination through intra-specific hybridization of desirable genotypes. This would be important in meeting the demand of the farmers, researchers and even consumers of the mango [21]. 


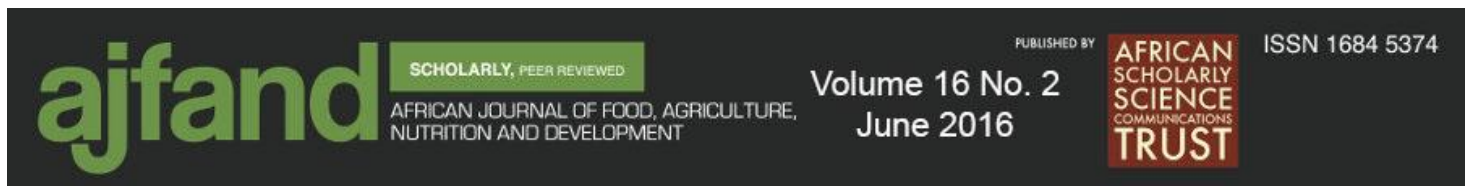

\section{CONCLUSION}

This study established that mango germplasm in the UAR possessed significant morphological variation among the studied accessions, presenting ample resources for breeding efforts. It has also given light on the possible parentage of accessions that have suffered confusion in their heritage, namely Apple, Ngowe, Batawi and Sabine. Highly correlated characters have been identified that will be useful in further improvement of mango. More importantly, the most useful non-fruit morphological traits that can be employed for distinguishing between mango varieties have been identified; they include: the color of young leaves, leaf attitude, leaf texture, growth habit, leaf blade length, leaf blade width and petiole length.

\section{ACKNOWLEDGEMENTS}

This research was funded by the Research Production and Extension (RPE) Unit of Jomo Kenyatta University of Agriculture and Technology (JKUAT), Kenya. 


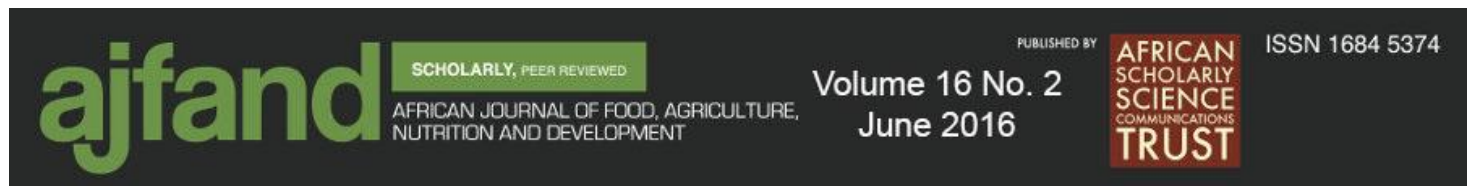

Table 1: A total of 98 mango accessions collected from the UAR region of eastern Kenya

\begin{tabular}{|c|c|c|c|c|c|}
\hline Variety & Location & Accession code given & Variety & Location & Accession code given \\
\hline \multirow[t]{17}{*}{ 1. Apple } & Ikalyoni & $\begin{array}{l}\text { 013A, 014A, 017A, 018A, } \\
\text { 020A, 035A, 036A }\end{array}$ & 10. Kent & Ikalyoni & $\begin{array}{l}\text { 06K2, 07K2, 09K2, } \\
010 \mathrm{~K} 2\end{array}$ \\
\hline & Ikangavya & 01A, 06A, 011A & & Kilala & $08 \mathrm{~K} 2$ \\
\hline & Kasikeu & $015 \mathrm{~A}$ & & Kiou & $05 \mathrm{~K} 2$ \\
\hline & Kilala & 03A, 04A, 09A, 029A, & & Kyamusoi & $02 \mathrm{~K} 2$ \\
\hline & Kiou & 023A, 025A, 026A, 027A, & & Station II & $01 \mathrm{~K} 2,03 \mathrm{~K} 2,04 \mathrm{~K} 2$ \\
\hline & & 034A & & & \\
\hline & Kithangathini & 012A & 11. Kitui & Mbiuni & $01 \mathrm{~K} 4$ \\
\hline & Kyamusoi & $02 \mathrm{~A}$ & 12. Maya & Kilala & 01M1, 02M1 \\
\hline & Kyanginywa & 016A, 019A, 021A, 022A & 13. Mombasa & Ikangavya & $01 \mathrm{M} 2$ \\
\hline & Malivani & $05 \mathrm{~A}$ & 14. Ndoto & Ikalyoni & 01N1 \\
\hline & Mbiuni & 028A, 030A,031A, 032A, & & Kilala & 02N1 \\
\hline & & 033A & & & \\
\hline & Sekereni & $024 \mathrm{~A}$ & 15. Ngowe & Ikalyoni & $07 \mathrm{~N} 3,08 \mathrm{~N} 3,014 \mathrm{~N} 3$ \\
\hline & Station I & 07A & & Kasikeu & $06 \mathrm{~N} 3$ \\
\hline & Station II & 010A & & Kilala & $02 \mathrm{~N} 3,010 \mathrm{~N} 3$ \\
\hline & Wote & 08A & & Kiou & $04 \mathrm{~N} 3,05 \mathrm{~N} 3,012 \mathrm{~N} 3$, \\
\hline & & & & & $013 \mathrm{~N} 3$ \\
\hline 2. Batawi & Kilala & 01B,02B & & Mbiuni & $09 \mathrm{~N} 3,011 \mathrm{~N} 3$ \\
\hline \multirow[t]{2}{*}{ 3. Dodo } & Kyanginywa & 02D, 03D & & Station I & $03 \mathrm{~N} 3$ \\
\hline & Wote & 01D & & Station II & $01 \mathrm{~N} 3$ \\
\hline 4. Haden & Kilala & $01 \mathrm{H}, 02 \mathrm{H}$ & 16. Nimrod & Wote & 01N0 \\
\hline
\end{tabular}




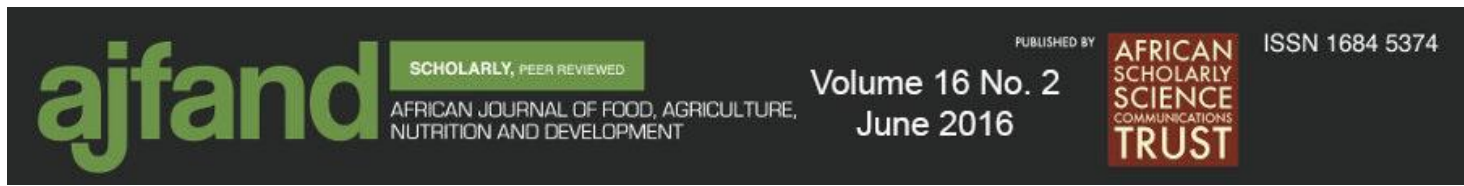

\begin{tabular}{|c|c|c|c|c|c|}
\hline 5. Indigenous & Kiou & $01 \mathrm{~L}$ & 17. Sabine & Kilala & $02 \mathrm{~S} 2,03 \mathrm{~S} 2$ \\
\hline \multicolumn{6}{|l|}{ I } \\
\hline 6. Indigenous & Sekereni & 02L & & Wote & $01 \mathrm{~S} 2$ \\
\hline \multicolumn{6}{|l|}{ II } \\
\hline \multirow[t]{7}{*}{ 7. Kasukari } & Ikalyoni & 04K1 & 18. Sensation & Kilala & $01 \mathrm{~S} 3$ \\
\hline & Ikangavya & $02 \mathrm{~K} 1$ & 19. Sikio la & Kyanginywa & $01 \mathrm{~S} 1$ \\
\hline & & & punda & & \\
\hline & Kasikeu & 06K1 & 20. Tommy & Kilala & 03T, 04T, 05T \\
\hline & Kikoko & 03K1 & & Station II & $02 \mathrm{~T}$ \\
\hline & Kilala & 01K1 & & Wote & $01 \mathrm{~T}$ \\
\hline & Kiou & $05 \mathrm{~K} 1$ & 21. Vandyke & Ikalyoni & $03 \mathrm{~V}$ \\
\hline 8. Katili & Kilala & $01 \mathrm{~K} 5$ & & Kilala & $01 \mathrm{~V}, 02 \mathrm{~V}$ \\
\hline 9. Keitt & Kilala & $01 \mathrm{~K} 3,02 \mathrm{~K} 3$ & & & \\
\hline
\end{tabular}




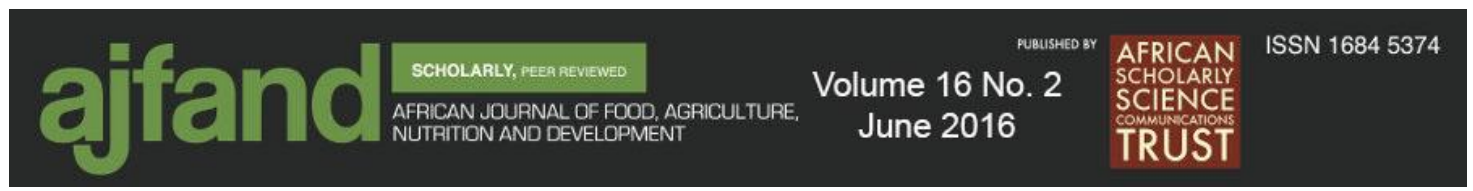

Table 2: Morphological descriptors used in the characterization of mango accessions from the UAR region of eastern Kenya
TRAIT
PHENOTYPIC CLASSES

Qualitative

\section{TREE}

Tree height

Stem circumference

Growth habit

Crown shape

branch)

Color of young leaf (CYL)

\section{LEAF}

Leaf attitude (in relation to 1 . Semi-erect 2. Horizontal 3. Semi-drooping

1. Light green 2. Light green with brownish tinge 3 . Light brick red 4.Reddish brown 5.Deep coppery tan

Color of fully mature leaf 1. Pale green 2. Green 3. Dark (CFL) green

Fragrance strength

Leaf blade shape (LBS)
1. Absent 2. Mild 3. Strong

1.Elliptic 2. Oblong 3. Ovate

4. Obovate 5. Lanceolate

6.Oblanceolate
Quantitative

Meters (m)

Inches 


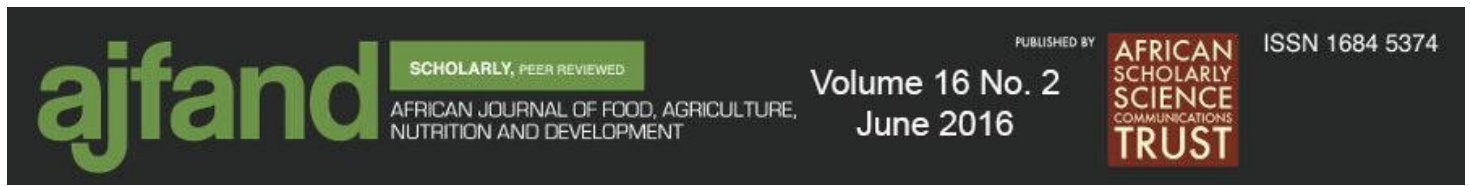

\begin{tabular}{lcc}
\hline Leaf blade length $(\mathrm{LBL})$ & -- & Centimeters $(\mathrm{cm})$ \\
Leaf blade width $(\mathrm{LBW})$ & -- & Centimeters $(\mathrm{cm})$ \\
Petiole length & -- & Centimeters $(\mathrm{cm})$
\end{tabular}

Leaf apex shape (LAS) $\quad$ 1. Obtuse 2. Acute 3.

Acuminate

Leaf base shape 1. Acute 2. Obtuse 3. Round

Leaf margin type $\quad$ 1. Entire 2. Wavy

Leaf texture 1. Coriaceous 2. Chartaceous

3. Membranous

Pelvinus thickness 1. Thin 2. Thick and tapering

Angle of secondary veins to 1 . Narrow $\left(<45^{\circ}\right) 2$. Medium

midrib $\quad\left(45-60^{\circ}\right) 3$. Wide $\left(>60^{\circ}\right)$

Presence of secondary veins 1 . Present 2 . Absent

Leaf pubescence 1. Present 2. Absent

Source: IPGRI (2006) 


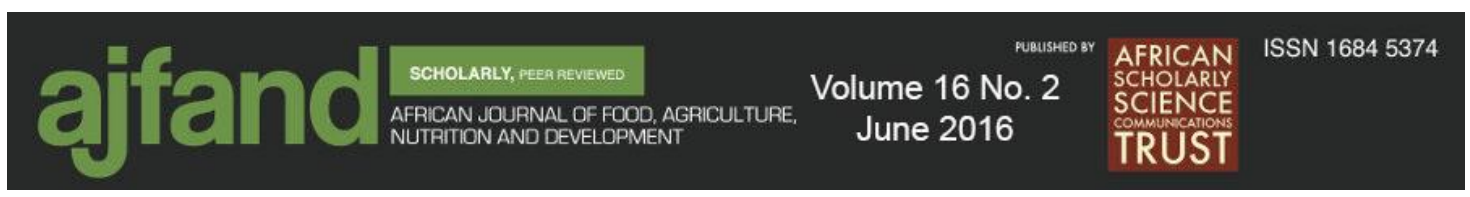

Table 3: Qualitative traits of mango accessions from the UAR region of eastern Kenya

\begin{tabular}{|c|c|c|}
\hline Descriptor trait & $\begin{array}{l}\text { Phenotypic classes } \\
\text { (\% of accessions with trait) }\end{array}$ & $\chi^{2}$ \\
\hline Leaf blade shape & $\begin{array}{l}1 \text { Elliptic (64.2\%), } 2 \text { Lanceolate (5.1\%), } \\
\text { 7*Lanceolate/Oblong (30.6\%) }\end{array}$ & $\chi^{2}=260.26 ; \mathrm{df}(84) ; \mathrm{P}=0.00$ \\
\hline Leaf apex shape & 2 Acute $(57.1 \%), 3$ Acuminate $(42.9 \%)$ & $\chi 2=98 ; \mathrm{df}(28) ; \mathrm{P}=0.00$ \\
\hline Leaf base shape & 1Acute $(20.4 \%), 2$ Obtuse $(79.6 \%)$ & $\chi^{2}=98 ; \mathrm{df}(28) ; \mathrm{P}=0.00$ \\
\hline Leaf margin type & 1Entire (70.4\%), 2 Wavy (29.6\%) & $\chi 2=67.98 ;$ df $(28) ; P=0.00$ \\
\hline Leaf attitude & 1Semi-erect (36.7\%), 2 Horizontal $(63.3 \%)$ & $\chi 2=35.81 ;$ df $(28) ; P=0.15$ \\
\hline Leaf texture & $\begin{array}{l}1 \text { Coriaceous }(27.6 \%), 2 \text { Chartaceous } \\
(69.4 \%), 3 \text { Membranous }(3.1 \%)\end{array}$ & $\chi 2=75.66 ; \mathrm{df}(56) ; \mathrm{P}=0.04$ \\
\hline Color of young leaf & $\begin{array}{l}1 \text { Light green }(18.4 \%), 2 \text { Light green with } \\
\text { brownish tinge }(53.1 \%), 4 \text { Reddish brown } \\
(14.3 \%), 5 \text { Deep coppery } \tan (14.3 \%)\end{array}$ & $\chi 2=294 ;$ df $(84) ; P=0.00$ \\
\hline Color of fully & $\mathbf{1}$ Pale green $(3.1 \%), \mathbf{2}$ Green $(38.8 \%), \mathbf{3}$ & $\chi 2=7.33 ; \mathrm{df}(56) ; \mathrm{P}=0.00$ \\
\hline grown leaf & Dark green $(58.2 \%)$ & \\
\hline Fragrance & 1 Absent (74.5\%), 2 Mild (25.5\%) & $\chi 2=62.04 ; \mathrm{df}(28) ; \mathrm{P}=0.00$ \\
\hline Growth habit & 1 Erect $(30.6 \%), 2$ Spreading $(69.4 \%)$ & $\chi 2=23.28 ; \mathrm{df}(28) ; \mathrm{P}=0.72$ \\
\hline Crown shape & $\begin{array}{l}1 \text { Oblong }(13.3 \%), 3 \text { Semi-circular }(62.2 \%) \text {, } \\
4 \text { Spherical }(24.5 \%)\end{array}$ & $\chi 2=128.6 ; \mathrm{df}(56) ; \mathrm{P}=0.00$ \\
\hline
\end{tabular}

* Trait displayed by mango from UAR not listed by IPGRI (2006) descriptors for mango (P<0.01 significance level). $\chi^{2}=\mathrm{Chi}$-square; $\mathrm{df}=$ degrees of freedom 


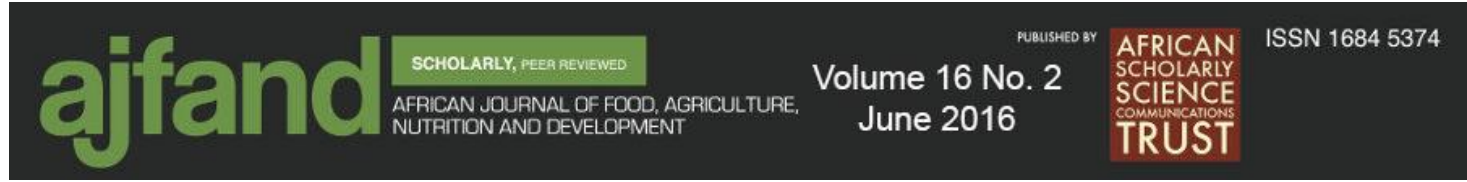

Table 4: Qualitative morphological traits of individual mango varieties from the

\begin{tabular}{|c|c|c|c|c|c|c|c|c|c|c|}
\hline \multicolumn{11}{|c|}{ UAR } \\
\hline Variety & $\begin{array}{l}\text { Leaf } \\
\text { Blade } \\
\text { Shape } \\
\end{array}$ & $\begin{array}{l}\text { Leaf } \\
\text { Apex } \\
\text { Shape } \\
\end{array}$ & $\begin{array}{l}\text { Leaf } \\
\text { Base } \\
\text { Shape } \\
\end{array}$ & $\begin{array}{l}\text { Leaf } \\
\text { margin }\end{array}$ & $\begin{array}{l}\text { Leaf } \\
\text { Attitude }\end{array}$ & $\begin{array}{l}\text { Leaf } \\
\text { Texture }\end{array}$ & $\begin{array}{l}\text { Color } \\
\text { Young } \\
\text { Leaf } \\
\end{array}$ & $\begin{array}{l}\text { Color } \\
\text { Mature } \\
\text { Leaf } \\
\end{array}$ & $\begin{array}{l}\text { Tree } \\
\text { Growth } \\
\text { Habit } \\
\end{array}$ & $\begin{array}{l}\text { Crown } \\
\text { Shape }\end{array}$ \\
\hline Apple & 1 & 2 & 2 & $\overline{1}$ & 2,1 & 2,1 & 2 & 3,2 & 2,1 & 3,4 \\
\hline Batawi & 7 & 3 & 2 & 1 & 1 & 2 & 2 & 3 & 2 & 3 \\
\hline Dodo & 7 & 3 & 2 & 2 & 2 & $1,2,3$ & 2 & 3 & 2 & 1 \\
\hline Haden & 7 & 3 & 1 & 1 & 1 & 2,1 & 1 & 3,2 & 1,2 & 3,4 \\
\hline $\begin{array}{l}\text { Indigenous } \\
1 \text { (Kiou) }\end{array}$ & 1 & 2 & 1 & 2 & 2 & 2 & 5 & 3 & 2 & 1 \\
\hline $\begin{array}{l}\text { Indigenous } \\
2 \\
\text { (Sekereni) }\end{array}$ & 2 & 3 & 2 & 2 & 2 & 2 & 5 & 2 & 2 & 4 \\
\hline Kasukari & 1 & 3 & 1 & 2 & 2 & 2 & 5 & 3 & 2 & 1 \\
\hline Katili & 1 & 3 & 1 & 2 & 2 & 3 & 5 & 1 & 2 & 1 \\
\hline Keitt & 1 & 2 & 2 & 1 & 2 & 2 & 2 & 3,2 & 1,2 & 3 \\
\hline Kent & 1 & 3 & 2 & 1 & 1,2 & 2,1 & 1 & $3,2,1$ & 2,1 & 3,4 \\
\hline Kitui & 1 & 2 & 1 & 1 & 2 & 2 & 5 & 3 & 2 & 4 \\
\hline Maya & 2 & 3 & 1 & 2 & 2 & 2 & 1 & 2 & 1,2 & 3 \\
\hline Mombasa & 1 & 3 & 1 & 2 & 2 & 2 & 5 & 3 & 2 & 1 \\
\hline Ndoto & 1 & 2 & 1 & 2 & 2 & 2 & 5 & 3 & 2 & 4 \\
\hline Ngowe & 7 & 3 & 2 & 1,2 & 1,2 & $2,1,3$ & 4 & $2,3,1$ & 2,1 & 3,4 \\
\hline Nimrod & 7 & 2 & 2 & 1 & 2 & 2 & 2 & 3 & 2 & 3 \\
\hline Sabine & 7 & 2 & 2 & 1 & 2 & 2 & 2 & 3,2 & 2,1 & 3 \\
\hline Sensation & 2 & 2 & 2 & 1 & 1 & 1 & 1 & 2 & 1 & 3 \\
\hline $\begin{array}{l}\text { Sikio la } \\
\text { punda }\end{array}$ & 2 & 3 & 1 & 2 & 2 & 2 & 5 & 2 & 2 & 1 \\
\hline $\begin{array}{l}\text { Tommy } \\
\text { Atkins }\end{array}$ & 7 & 2 & 2 & 1 & 2,1 & 2,1 & 2 & 3,2 & 2,1 & 3,4 \\
\hline Vandyke & 7 & 2 & 1 & 1 & 2,1 & 1,2 & 1 & 3,2 & 2,1 & 3 \\
\hline
\end{tabular}

Key used is as on Table 3 


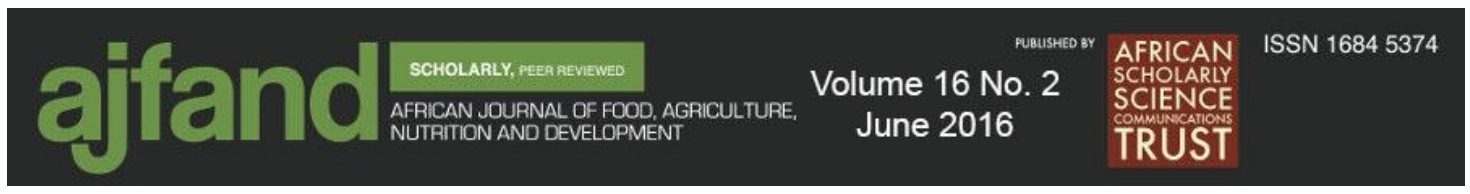

Table 5: Quantitative traits of mango accessions from the UAR region of eastern

\begin{tabular}{lcccccc}
\multicolumn{1}{c}{ Kenya } & \multicolumn{1}{l}{ Minimum } & Maximum & Mean & Mean & F & P Value \\
\hline Trait & value & value & & square & \\
& & & & & & \\
& $9.14 \mathrm{~cm}$ & $29 \mathrm{~cm}$ & $16.96 \pm 0.50$ & 30.68 & 1.35 & 0.16 \\
LBL & $2.59 \mathrm{~cm}$ & $7.95 \mathrm{~cm}$ & $4.59 \pm 0.14$ & 2.35 & 1.45 & 0.11 \\
LBW & $2 \mathrm{~cm}$ & $8.25 \mathrm{~cm}$ & $4.68 \pm 0.13$ & 2.19 & 1.47 & 0.10 \\
Petiole length & $2 \mathrm{~m}$ & $10 \mathrm{~m}$ & $5.62 \pm 0.24$ & 16.67 & 14.30 & 0.00 \\
Height & $20.8 \mathrm{inches}$ & $101.2 \mathrm{inches}$ & $42.81 \pm 2.43$ & 1949.60 & 38.85 & 0.00 \\
Stem circumference & & & & & &
\end{tabular}

$\mathbf{P}<0.01$ significance level

Key:

LBL- Leaf blade length

LBW- Leaf blade width 


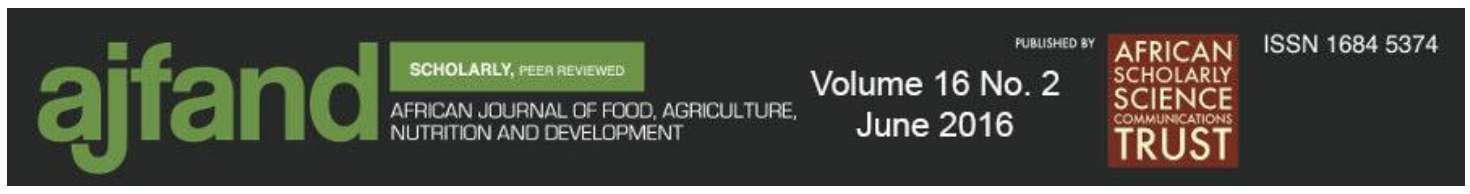

Table 6: Principal component analysis showing the eigen values, percentage variability, percentage cumulative variability and eigen vectors for mango accessions traits from the UAR region of eastern Kenya

\begin{tabular}{|c|c|c|c|c|c|c|}
\hline & \multicolumn{6}{|c|}{ Principal Components (PC) } \\
\hline & PC 1 & PC 2 & PC 3 & PC 4 & PC 5 & PC 6 \\
\hline Eigen value & 5.238 & 1.989 & 1.519 & 1.258 & 1.040 & 0.975 \\
\hline Variability (\%) & 32.738 & 12.430 & 9.492 & 7.863 & 6.503 & 6.096 \\
\hline \multirow[t]{2}{*}{ Cumulative \% } & 32.738 & 45.168 & 54.660 & 62.524 & 69.026 & 75.122 \\
\hline & \multicolumn{6}{|c|}{ Eigen vectors } \\
\hline LBS & -0.030 & -0.021 & 0.545 & 0.319 & 0.383 & -0.282 \\
\hline LBL & 0.161 & 0.582 & 0.268 & -0.074 & -0.041 & 0.083 \\
\hline LBW & 0.176 & 0.582 & 0.124 & -0.114 & -0.123 & 0.137 \\
\hline Petiole Length & 0.089 & 0.241 & -0.201 & -0.356 & 0.490 & -0.429 \\
\hline LAS & 0.194 & -0.184 & 0.470 & 0.184 & -0.195 & -0.196 \\
\hline Leaf Base Shape & -0.301 & 0.037 & 0.067 & -0.074 & 0.267 & 0.024 \\
\hline Leaf Margin & 0.345 & -0.049 & 0.242 & -0.092 & 0.038 & 0.102 \\
\hline Leaf Attitude & 0.174 & 0.039 & -0.265 & 0.259 & 0.370 & 0.420 \\
\hline Leaf Texture & 0.156 & -0.357 & 0.101 & -0.304 & 0.373 & 0.129 \\
\hline CYL & 0.316 & 0.009 & 0.121 & -0.087 & 0.263 & -0.087 \\
\hline CFL & 0.058 & 0.224 & -0.322 & 0.614 & 0.192 & -0.247 \\
\hline Fragrance & 0.332 & -0.130 & -0.172 & -0.201 & 0.038 & -0.005 \\
\hline Height & 0.373 & -0.047 & -0.130 & -0.016 & -0.216 & -0.119 \\
\hline Stem circumference & 0.405 & -0.019 & -0.140 & -0.008 & -0.133 & -0.095 \\
\hline Growth habit & 0.162 & -0.027 & 0.125 & 0.222 & 0.179 & 0.582 \\
\hline Crown shape & -0.301 & 0.160 & 0.107 & -0.268 & 0.077 & 0.195 \\
\hline
\end{tabular}

Values in bold indicate the descriptors that contributed most to the specific principal component Key:

LBS- Leaf blade shape, LBL- Leaf blade length, LBW- Leaf blade width, LAS- Leaf apex shape CYL- Color of young leaf, CFL- Color of fully mature leaf 


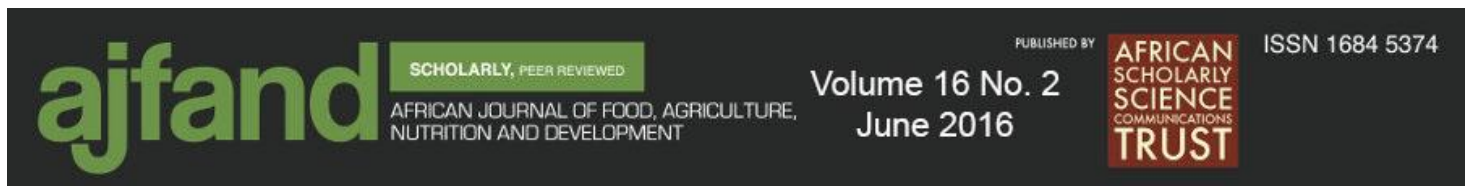

\section{REFERENCES}

1. Duval MF, Bunel J, Sitbon C, Risterucci AM, Calabre C and F Le Bellec Genetic Diversity of Caribbean mangoes (MiL) using microsatellite markers. $8^{\text {th }}$ International Mango Symposium, February 5-10, 2006, Sun City, South Africa, 2006.

2. HCDA. Horticultural Crops Development Authority HCDA. Export Statistics. Website: http://www.hcda.or.ke/Resource_centre.htm, 2010. Accessed 08.08.14.

3. Ravishankar KV, Lalitha A, Dinesh MR and L Anand Assessment of genetic relatedness among mango cultivars of India using RAPD markers. J. Hortic. Sci. Biotechnol. 2000; 75(2):198-201.

4. Griesbach J Mango Growing in Kenya. ICRAF, Nairobi, Kenya, 2003.

5. Hawkes J Genetic Conservation of World Crop Plants. Academic Press, London, 1991.

6. Kehlenbeck K, Rohde E, Njuguna JK, Omari F, Wasilwa $\mathbf{L}$ and $\mathbf{R}$ Jamnadass Mango cultivar diversity and its potential for improving mango productivity in Kenya. In: Transforming agriculture for improved livelihoods through agricultural product value chains. Proceedings of the $12^{\text {th }}$ KARI biennial scientific conference, Kenya Agricultural Research Institute, Nairobi, Kenya, $2010 ; 657-665$.

7. Wahdan MT, Abdelsalam AZ, El-Naggar AA and MA Hussein Preliminary horticultural studies to describe and identify two new Egyptian mango strains using DNA fingerprinting. J. Amer. Sci. 2011; 7(2): 641-650.

8. Watson JW and PB Eyzaguirre Proceedings of the Second International Home Gardens Workshop, 17-19 July 2001, Witzenhausen, Federal Republic of Germany, IPGRI, Rome, Italy, 2002.

9. IPGRI. International Plant Genetic Resources Institute. Descriptors for mango (Mangifera indica). International Plant Genetic Resources Institute, Rome, Italy, 2006.

10. SPSS. Inc. PASW Statistics for Windows, Version 18.0. Chicago: SPSS Inc. Released 2009.

11. FAO. Food and Agriculture Organization of the United Nations. Value Chain Analysis: A Case Study of Mangoes in Kenya, FAO (Prepared by the: Sugar and Bevarages Group, Raw Materials, Tropical and Horticultural Products Service, Commodities and trade Division), 2003.

12. Njuguna JK, Wepukhulu SB and S Wanjala Mango cultivar evaluation programme in Kenya. Acta. Hort. 2009; 820: 133-135. 


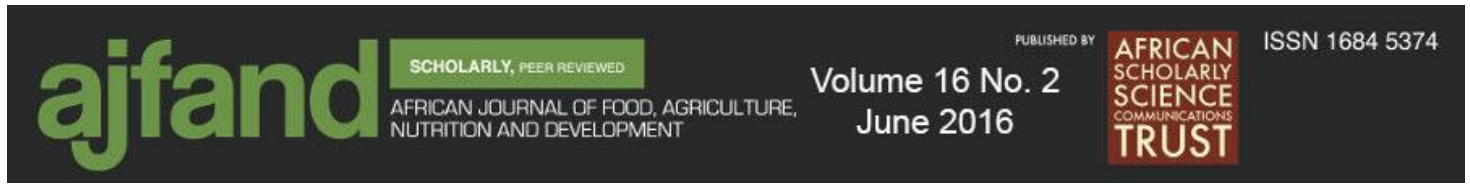

13. Hamilton RA Origin and Classification of Mango Varieties in Hawaii. Website: http: // www.ctahr.hawaii.edu. Accessed on 20.08.15.

14. ABD. Agricultural Business Development. The Mango Sub-Sector in Eastern Region. The Results of the Mango Tree Census and Baseline Survey for Eastern Region. Final Report. Institution Development \& Management Services, Mombasa, Kenya, 2011.

15. Galvez-Lopez D, Salvador-Figueroa M, Adriano-Anaya L and N MayekPerez Morphological Characterization of Native Mangoes from Chiapas, Mexico. Subtrop. P. Sci. 2010; 62:18-26.

16. Mussane CRB, Biljon AV and $\mathbf{L}$ Herselman Morphological and genetic characterization of mango varieties in Mozambique, Second RUFORUM Biennial Meeting 20 - 24 September 2010, Entebbe, Uganda, 2010.

17. Sennhenn A, Prinz K, Gebauer J, Whitbread A, Jamnadass $\mathbf{R}$ and $\mathbf{K}$ Kehlenbeck Identification of mango (Mangifera indica L.) landraces from Eastern and Central Kenya using a morphological and molecular approach. Genet. Resour. Crop Evol. 2014; 61:7-22.

18. Cruz CD, Regazzi JA and PCS Carneiro Modelos biométricosaplicados ao melhoramento gene'tico. Editora UFV,Vic sosa. 2004; 377-413.

19. Oliveira EJ, Pereira-Dias NL and JLL Dantas Selection of morpho-agronomic descriptors for characterization of papaya cultivars. Euphytica. 2012; 185:253265.

20. IBPGR. International Board for Plant Genetic Resources. Descriptors for Papaya. Rome. 1988; 1-33.

21. Asudi GO, Ombwara FK, Rimberia FK, Nyende AB, Ateka EM, Wamocho LS, Shitanda D and A Onyango Morphological diversity of Kenyan papaya germplasm. Afr. J. Biotechnol. 2010; 9: 8754-8762.

22. Santos-Ribeiro ICN, Santos-Fernandes CA and FP Neto-Lima Morphological Characterization of Mango (Mangifera indica) Accessions Based on Brazilian Adapted Descriptors. J. Agr. Sci. Tech. 2013; 3: 798-806.

23. Aikpokpodion PO Assessment of genetic diversity in horticultural and morphological traits among papaya (Carica papaya) accessions in Nigeria. Fruits. 2012; 67: 173-187.

24. Ocampo JP, D'Eeckenbrugge GC, Bruyère $S$, DE Bellaire $L L$ and $P$ Ollitrault Organization of morphological and genetic diversity of Caribbean and Venezuelan papaya germplasm. Fruits. 2006; 61: 25-37. 